\title{
MODERNIDADE E CIDADE SOB AS LENTES DE ÁLVARO DE CAMPOS
}

\author{
Silvana Maria Pantoja dos Santos ${ }^{1}$
}

\begin{abstract}
RESUMO: A modernidade é marcada por uma série de desdobramentos sociopolíticos que culminaram em uma nova maneira dos artistas compreenderem o mundo. Movido pelos sistemas de representações do final do século XIX e início do século XX, o mundo foi alterado pela quebra de paradigmas. Diante disso, objetivamos com este trabalho analisar a emergência da cidade de Lisboa sob o olhar de Álvaro de Campos. Para tanto, o pensamento de Benjamin é fundamental nessa discussão. A partir da análise da transição pela qual passou a sociedade europeia, em particular a cidade de Paris. Benjamin traduz o espírito moderno impactado pela contingência e fluidez dos novos tempos, delineado por outras formas de socialização. Álvaro de Campos ao expor a fisiologia da cidade, desnuda as impressões do homem marcado pela mobilidade do novo mundo ampliado e difuso, desencadeando uma visão fragmentada da cidade que se dilata.
\end{abstract}

PALAVRAS-CHAVE: Modernidade; Cidade.

\section{MODERNITY AND CITY THROUGH EYES OF ÁLVARO DE CAMPOS}

\begin{abstract}
Modernity is marked by a series of socio-political developments that culminated in a new way for artists to understand the world. Moved by systems of representations of the late nineteenth and early twentieth century, the world was changed by the shift in paradigm. Therefore, this work aimed to analyze the emergence of Lisbon under the gaze of Alvaro de Campos. To that end, Benjamin's thought is central to this discussion. From the analysis of the transition undergone by European society, particularly the city of Paris. Benjamin reflects the modern spirit impacted by the contingency and fluidity of the new era, shaped by other forms of socialization. Alvaro de Campos, by exposing the physiology of the city, discloses the impressions of the man marked by the mobility of extended and diffuse new world, triggering a fragmented view of the city that expands.
\end{abstract}

KEY-WORDS: Modernity; City.

\footnotetext{
${ }^{1}$ Doutoranda em Teoria Literária pela Universidade Federal de Pernambuco - UFPE. Prof ${ }^{a}$ de Literatura Brasileira e Portuguesa da Universidade Estadual do Piauí - UESPI e da Universidade Estadual do Maranhão UEMA. Integrante do grupo de pesquisa INTERLIT da UESPI.
} 


\section{Modernidade no pensamento benjaminiano}

O pensamento de Walter Benjamin sobre a Paris do Século XIX torna-se um de seus trabalhos mais conhecidos e referência básica para a compreensão da postura do homem moderno na cidade que se diferencia. "As passagens são qualquer coisa de intermédio entre a rua e o interior", assim Benjamin (2007, p. 39) se reporta aos amplos espaços que rasgam a cidade no século XIX, a partir do ideal de modernização de Hausmann. As passagens abrigam onibus, trem, multidão em movimentos. Somam-se a elas as galerias, precursoras dos shopping centers, que se mostram sedutoras e modernas.

Com o surgimento dos grandes centros urbanos, um novo estilo de vida emerge nas ruas das cidades. Nos cafés, bares e centros comerciais, pessoas apressadas se acotovelam e se revezam. Imagem constante do estilo de vida parisiense com todas as complexidades de um grande centro. Assim, a cidade acabou se moldando para acomodar o crescimento econômico, direcionando a sociedade daquele momento histórico a uma nova forma de estruturação. Nesse cenário, surgem também outras exigências: o aumento das horas de trabalho, as obrigações, o ponto, as reuniões e a intensificação no grau de vigilância sobre os trabalhadores que têm seus comportamentos controlados, são as imagens mais recorrentes na cidade moderna. Por sua vez, a classe operária adotou um ritmo automatizado em consonância com o movimento das fábricas, das engrenagens. Tudo a sua volta passa a ser indiferente.

O delinear da cidade que se vislumbra naquele momento corrobora para o novo perfil de homem moderno, novo intérprete da vida citadina: o flâneur, passeador desenraizado, solitário, envolto à multidão. Lentamente o flâneur se deleita com as vitrines de luxo das passagens e logo atinge as ruas em observação. Com olhar carregado de sentido e reflexão, silenciosamente observa a paisagem e as pessoas. Nada é imune ao seu olhar: multidão, rostos anônimos, fachadas de prédios, galerias... Esse novo mundo de embriaguez torna-se o espaço perfeito à flânerie.

No lugar do ritmo frenético das pessoas atraídas pelo ruído das engrenagens que, maquinalmente, vão ao encontro delas, o flâneur, com passos demorados, deambula pelas ruas envolto em uma aparente ociosidade, atitude que contraria o dinamismo da cidade em torno da divisão de trabalho. No entanto, a flânerie não pode ser confundida com ócio. Apesar de não participar da lógica do progresso, nem da força de produção, o flanêur não renega a sua individualização: negar-se a compartilhar com o ritmo frenético da multidão já é uma tomada de posição. 
A multidão desperta no homem que a ela se entrega uma espécie de embriaguez acompanhada de ilusões muito particulares, de tal modo que ele se gaba, vendo o passante levado pela multidão, de tê-lo classificado a partir de seu exterior, de tê-lo reconhecido em todas as dobra de sua alma.

(BENJAMIN, 2007, p.62)

No ir e vir da agitação dos transeuntes, os rostos desconhecidos são passíveis de conjecturas acerca de atividade profissional, classe social, personalidade, angústias e desejos, resultado do choque provocado pelo olhar. É através do olhar do flâneur que a cidade de Paris ganha um novo significado diante da visão da fantasmagoria. Nesse sentido, Benjamim afirma:

Se Giradoux tem razão e se a maior sensação de liberdade humana é flanar ao longo do curso de um rio, então aqui a mais completa ociosidade, e portanto a mais prazerosa liberdade ainda conduz livro e livro adentro[...]. Paris é um grande salão de biblioteca atravessado pelo Sena.[...]. Esta cidade se inscreveu tão indelevelmente na literatura porque nela mesma atua um espírito aparentado aos livros. (BENJAMIM,1987,p.195).

Benjamim, ao analisar a obra de Baudelaire, tece considerações sobre a nova noção de indivíduo vinculando-o a dois temas: a emergência do flâneur como tradução do espírito de mobilidade que se inaugura com a modernidade e a aproximação da atividade da flânerie com o trabalho intelectual. A poesia de Baudelaire situa o sujeito poético nas vias públicas que vai desvelando com o olhar elementos que compõe a nova paisagem, ao tempo em que ele próprio se porta como um exímio flâneur, sempre em meio à multidão.

Baudelaire não se atém a descrições como alguns de seus contemporâneos. Ao contrário, é seduzido por imagens pulsantes do espaço citadino. Mesmo em temas que, por si só sugerem calmaria, como a alvorada, Baudelaire consegue sentir "nas ruas desertas" qualquer rumor silencioso. Como uma câmara fotográfica, focaliza pontos específicos do magma urbano e os registra, sem antes deixar as marcas de suas impressões que podem vir em forma de repulsão ou atração.

A vida na metrópole, envolta em um deslocamento veloz de transeuntes, de veículos, retira das pessoas a capacidade de percepção, desautoriza a flânerie. $\mathrm{Na}$ contramão do desenvolvimento, o flâneur solitário caminha com olhar debruçado sobre a cidade, procurando desviar-se de qualquer forma de "acomodação" à nova realidade. Nessa concorrência desleal, o flâneur não resiste por muito tempo, desaparece ameaçado pela crise da estrutura social, do ritmo azafamo da população e do progresso desenfreado. Desaparece porque o ritmo 
acelerado das ruas não comportava a sua lentidão, mas a experiência incomum da flânerie, movida pela nova circunstância urbana, abre alas para escritores posteriores expressarem suas vivências com e na cidade.

\section{2 Álvaro de Campos e a cidade}

O início do século XX foi efetivamente a época em que a humanidade assistiu a explosão tecnológica, a introdução do dinamismo capitalista que orientou o desenvolvimento econômico proporcionando profundas transformações urbano-sociais. $O$ mundo civilizado surge com as fábricas fumegando com ânsia, emaranhado de fios telefônicos, de canos de gases, de ônibus, automóveis e carroças atrofiantes, com a luminosidade dos cafés e das grandes avenidas com passantes frenéticos. Fernando Pessoa é dessa época, e não podia deixar de ter consciência das transformações radicais por que passava o mundo. Por meio de cartas trocadas com o amigo Mário de Sá Carneiro que se encontrava em Paris em 1912, Pessoa toma conhecimento da renovação nas artes, no entanto, Portugal mostrava-se aquém do processo de modernização.

A tomada de consciência surge com a Geração Orfeu que escandaliza a sociedade lisboeta. A intenção do grupo era provocar o passadismo, chocar a burguesia, para tanto, seus textos apresentam caráter vanguardista tanto na forma quanto no conteúdo. As imagens surgem permeadas de sensações, e essa emergência do sensacionismo - movimento em que os poetas buscavam expressar a fusão de sensações distintas - anunciará a vinda do paroxismo futurista, já marcante em Ode Triunfal. Assim os poetas desse momento imprimem um outro ritmo à capital portuguesa.

Pessoa, com alma inquieta, dedicou-se a se desdobrar em vários eus, o que o imortalizou como poeta do fingimento. Foi igualmente excêntrico e único. A sua sensibilidade em multiplicar-se reside nas diferentes formas de percepção do mundo. Das suas criações, Álvaro de Campos é o extremo oposto dos demais heterônimos, é o filho indisciplinado de Pessoa. No entanto, a exemplo de Caeiro, Campos tem data de nascimento e morte (1890-1935).

Caracterizado biograficamente por Pessoa como vanguardista e cosmopolita, espelha este perfil particularmente nos poemas em que escolta, em tom futurista, a civilização moderna e os valores do progresso. Sendo engenheiro naval e viajante, sua sensação e percepção tornam-se aguçadas, possibilitando olhares múltiplos para a realidade circundante. Campos é de um lugar e de lugar algum, por isso seu olhar de viajante não se demora em contemplações, não é o olhar de um observador da elegância, do requinte, da perfeição. Campos vê a cidade em relances de 
simultaneidade, em todos os seus aspectos, inflamado pela ânsia de reter tudo que lhe seja possível. O seu prazer constitui fixar residência no movimento.

Encanta-se pelo mundo moderno com todos os seus elementos urbanizados e pela velocidade. O olhar do poeta pessoano é crítico e definidor do real. No âmago da efervescência da cidade moderna, da multidão, dos contrastes, do efêmero, tem consciência da perda da totalidade, pela fragmentação e dispersão. Diante disso, este artigo pretende analisar, na esteira de Benjamin, a singular percepção poética de Álvaro de Campos sobre o espaço urbano no rasto do novo e veloz comboio da modernidade.

O flâneur de Álvaro de Campos é futurista, encanta-se com o progresso, mistura-se à massa, mas é em essência um individuo solitário, nesse aspecto aproxima-se do flâneur de Baudelaire. É o que podemos comprovar se aproximarmos a recorrência do acaso, do anonimato de uma mulher em Acaso de Álvaro de Campos à figura feminina em a uma passante de Baudelaire.

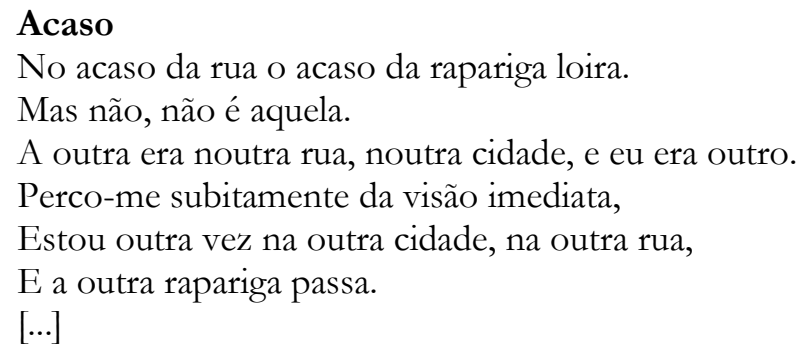

No poema A uma passante, o sujeito poético de Baudelaire é fisgado pelo olhar de uma transeunte. Rapidamente é movido por um sentimento encantatório, cuja duração corresponde ao instante do olhar. Semelhante a Baudelaire, no poema Acaso o sujeito poético de Campos põe-se a observar a "rapariga loira" no "acaso da rua" que o magnetiza, no entanto, esta não se confunde com outra rapariga loira visualizada em uma outra cidade, mas a semelhança o deixa estonteado porque em meio à massa as pessoas se homogeneízam. Ambos poemas são movidos pelo enigma que envolve o relance do olhar, causando epifania.

A dialética entre o desejo de permanecer e a necessidade de prosseguir resulta na impossibilidade de apreensão, reforçando a fantasmagoria tão difundida por Benjamin. A experiência do choque, como uma vertigem, imobiliza os sujeitos poéticos diante da visão fugidia da passante. O encontro ao acaso, como sugere Campos, pode ser entendido com uma nova forma de experiência no contexto urbano: da atração que surge impossibilitada pela brevidade do contato. Sendo fugidio, o contato se inscreve na linha da pressa que se materializa apenas pelo 
olhar: visão insólita que se desprende rapidamente, sem que antes provoque perplexidade. $\mathrm{O}$ mesmo procedimento é possível perceber no poema O florir do encontro casual de Campos.

\author{
$[\cdots]$ \\ O florir do encontro casual \\ Dos que hão sempre de ficar estranhos... \\ O único olhar sem interesse recebido no acaso \\ Da estrangeira rápida... \\ O olhar de interesse da criança trazida pela mão \\ Da mãe distraída... \\ As palavras de episódio trocadas \\ Com o viajante episódico \\ $\mathrm{Na}$ episódica viagem... \\ Grandes mágoas de todas as coisas serem bocados... \\ Caminho sem fim...
}

Outrora, ao homem era atrelada uma identidade que o diferenciava dos demais integrantes da sociedade na qual se inseria, com o crescimento urbano, o homem passa a ser um "passante" em meio à multidão, isso favorece a "perda de vestígios que acompanha o desaparecimento do ser humano nas massas das cidades grande" (BENJAMIN, 1989, p. 44). Sem rosto, sem nome, sem identidade, apenas "um transeunte que (...) olha com uma estranheza casual", apenas a "estrangeira rápida", o "viajante episódico", todos sinônimos de passagem, e a constatação com gosto amargo de que no contexto da modernidade, sobretudo nos centros urbanos, as coisas existem para "serem bocadas". A dialética entre o mistério que se inscreve em cada rosto e a revelação possível através do breve olhar é uma tentativa inútil de sustentar a individualização dos sujeitos que se homogeneízam na multidão.

O poema que segue é uma expressiva homenagem ao poeta Cesário Verde, prenunciador da modernidade. O poeta Realista, com o olhar voltado ao cotidiano lisboeta e aos atributo de seus habitantes, antecipa a poesia moderna de 1915 e exerce forte influência sobre Fernando Pessoa, mais precisamente sobre Álvaro de Campos. Cesário volta-se para aspectos da realidade urbana antes ignorada por seus contemporâneos: o proletário, os pequenos trabalhadores, as belas e feias mulheres que o olho capta na rua ou no quarto, enfim, Cesário passa a ser o pintor dos ambientes. 


\section{Crepúsculo}

Ah o crepúsculo, o cair da noite, o acender das luzes nas grandes cidades E a mão de mistério que abafa o bulício,

E o cansaço de tudo em nós que nos corrompe

Para uma sensação exacta e precisa e activa da Vida!

Cada rua é um canal de uma Veneza de tédios

E que misterioso o fundo unânime das ruas,

Das ruas ao cair da noite, ó Cesário Verde, ó Mestre,

Ó do «Sentimento de um Ocidental»!

Que inquietação profunda, que desejo de outras coisas.

$$
[\cdots]
$$

A iluminação da cidade é também matéria da poesia de Cesário, o que justifica, aqui, o diálogo entre os poetas. A cidade gradativamente se reverte de brilho e luminosidade a partir do gesto rotineiro do acendedor de lampião a gás, sempre ao entardecer, enquanto o crepúsculo se despede sem alarde. Para Benjamin, a implantação dos lampiões a gás nas galerias corrobora para que o flâneur sinta-se cada vez mais à vontade em espaços públicos.

O fenômeno da rua como interior, fenômeno em que se concentra a fantasmagoria do flâneur, é difícil separar da iluminação a gás. As primeiras lâmpadas a gás arderam nas galerias. (...) Isso elevou o grau de segurança da cidade; fez a multidão em plena rua sentir-se, também à noite, como em sua própria casa; removeu do cenário grande o céu estrelado e o fez de modo mais radical que os seus prédios altos. (BENJAMIN, 1989, p. 47)

O brilho do lampião diante do crepúsculo é tímido e vai se fortalecendo sem quebrar a harmonia com a natureza, porém, com a chegada da eletricidade, a ruptura com a paisagem natural é brusca e o entardecer passa a ser violentamente invadido pela iluminação instantânea. Outro aspecto impactante a ser evidenciado no contexto urbano é a perda do diferencial. A população é classificada por grupos, em conjunto de semelhantes: o dos proprietários e o dos funcionários, o dos vendedores e o dos clientes, o dos trabalhadores e dos pedintes, passando as pessoas a serem vistas como sujeitos coletivos em meio à multidão. Cesário Verde e, posteriormente, Campos captam na multidão as figuras sem rostos, sem nome, sem identidade.

Cruzou por mim, veio ter comigo, numa rua da Baixa

Aquele homem mal vestido, pedinte por profissão que se lhe vê na cara, Que simpatiza comigo e eu simpatizo com ele;

E reciprocamente, num gesto largo, transbordante, dei-lhe tudo quanto tinha

(Exceto, naturalmente, o que estava na algibeira onde trago mais dinheiro: 
A individualização é ironizado pelo sujeito poético no instante em que a ajuda se efetiva de modo mesquinho. Ao Outro, estranho, nos centros urbanos, não é permitida a proximidade, mas apenas o ato "solidário" do auxílio. Figuras sem rosto são reforçadas em outros poemas de Campos, como em Acordar:

A mulher que chora baixinho Entre o ruído da multidão em vivas...

$\mathrm{O}$ vendedor de ruas, que tem um pregão esquisito, Cheio de individualidade para quem repara...

O arcanjo isolado, escultura numa catedral,

Siringe fugindo aos braços estendidos de Pã,

Tudo isto tende para o mesmo centro,

Busca encontrar-se e fundir-se

Na minha alma.

$[\ldots]$

É nesse ambiente de desconhecidos e de pouca autenticidade, num paradoxo entre multidão e solidão, que a figura do flâneur atua e, consequentemente, Benjamin classifica como "o homem das multidões". É certo que a flânerie de Campos apresenta menos traços de Baudelaire que de Poe. Em Baudelaire o homem sente-se acomodado e protegido em meio ao burburinho cotidiano da cidade, ao ponto de se dispersar na massa, como diz Benjamin (1989, p.47) Baudelaire "amava a solidão, mas a queria na multidão". Em Poe o homem é alguém que não se sente seguro em meio à multidão, mas seus personagens dependem dela: o detetive que a vasculha numa busca incessante e o fugitivo que precisa dela para se camuflar, numa "multidão a perder de vista, onde ninguém é para o outro nem totalmente nítido, nem totalmente opaco" (BENJAMIN, 1989, p.46). Para Poe, a cidade torna-se ameaçadora porque pode tanto esconder quanto revelar o enigma.

O filho indisciplinado das sensações movimenta-se de modo alucinante como o detetive de Poe, sempre atento ao longo do caminho a desvelar mistérios decompostos em fragmentos de realidade. Suas ações são guiadas pela agitação que ora se aproxima, ora se distancia das cenas observadas.

Ah, o som do jantar nas casas felizes!

Passo e os meus ouvidos veem para dentro das casas.

O meu exílio natural enternece-se no escuro

Da rua meu lar, da rua meu ser, da rua meu sangue.

Agora, a caminho do carro eléctrico do términus de onde se volta à cidade,

Passo, bandido, metafísico, sob a luz dos candeeiros afastados, E na sombra entre os dois candeeiros afastados tenho vontade de não seguir. 
Mas apanharei o eléctrico.

$[\ldots]$

Este poema faz lembrar, às avessas, um conto de Poe, cujo narrador capta uma cena de rua a partir da janela de um espaço público. De posse de binóculo, como em situação para assistir a uma peça teatral, cruza o obstáculo que o separa da rua e adentra imaginariamente a multidão sentindo-se revigorado.

Em Campos, para capturar a cena privada é preciso estar na rua, ser habitante de espaços exteriores. Embora seja possuído por um desejo incomensurável de vivência familiar, motivado pela realidade de outrem, o observador é arrancado dali fisgado pelo rumor da cidade, seu "exílio natural", e segue em direção ao elétrico.

Apesar da aproximação com personagens de Poe, o sujeito poético de Campos apresenta traços que são comuns a flânerie também de Baudelaire no instante em que reconhece a solidão na impossibilidade de compartilhar vivências.

Como poeta das sensações, os sentidos encontram-se em alerta ante os movimentos da cidade. O olhar poético se alonga e se reveste em audição quando "ouvidos veem para dentro das casas". Nessa concepção o corpo é entendido como mediador da relação entre sujeito e mundo. Sua percepção encravada no olho do furacão da modernidade já não permite uma visão totalizadora, abarca apenas fagulhas descritas em movimentos rápidos de modo inquietante, interrogativo.

\section{Acordar}

Acordar da cidade de Lisboa, mais tarde do que as outras,

Acordar da Rua do Ouro,

Acordar do Rocio, às portas dos cafés,

Acordar

E no meio de tudo a gare, que nunca dorme,

Como um coração que tem que pulsar através da vigília e do sono.

Toda a manhã que raia, raia sempre no mesmo lugar,

Não há manhãs sobre cidades, ou manhãs sobre o campo.

À hora em que o dia raia, em que a luz estremece a erguer-se

Todos os lugares são o mesmo lugar, todas as terras são a mesma,

E é eterna e de todos os lugares a frescura que sobe por tudo.

$[\ldots]$

A cidade de Lisboa se alarga em versos e acorda para a modernidade. Campos põe em movimento um Eu deambulador que, com olhos atentos, passa a registrar pequenos recortes, insinuações de uma modernidade tardia. É um Eu dialeticamente solitário e múltiplo. 


\section{Por uma breve reflexão inconclusa}

O homem moderno está fadado a seguir seu curso sem deuses para conduzi-lo, isso lhe retira a esperança e, no lugar, ergue-se a muralha da solidão e do risco, sem direito à apelação. Como afirma Benjamin (1987, p. 210), "tanto no céu como na terra tudo se tornou indiferente à sorte dos seres humanos". A cidade que se tematiza na modernidade permite o olhar, mas nega o encontro. Envolta em labirinto, como uma serpente em convulsão, a cidade devora a multidão numa volúpia, transformando as pessoas em seres anônimos e solitários.

Desse modo, o grande dilema do poeta moderno, Campos nesse particular, é filtrar imagens de uma nova realidade embutida em uma cidade dilatada, que se diferencia da cidademuralha. Outrora, esta dava a sensação de proteção e solidez na sua estrutura de fortaleza, refletindo na vivência em sociedade. Os homens não se sentiam solitários porque suas ações vislumbravam interesses coletivos, configurando-se numa totalidade.

Abandonados pelos deuses e jogados à própria sorte, os poetas modernos, diante da incerteza desse novo mundo, ampliado e difuso, desencadeiam uma visão fragmentada do espaço citadino e se arremessam a uma desmedida busca para dizer o fluido. Assim, as imagens dos elementos da cidade de Lisboa, perceptíveis às lentes de Álvaro de Campos resultam da impossibilidade de apreensão da totalidade negada. Resta-lhe apenas reconstruir imagens de uma realidade em mutação que surgem em fragmentos, dispersões, lampejos, relâmpagos. 


\section{Referências}

BAUDELAIRE, Charles. O pintor da vida moderna. Tomaz Tadeu (org.) Belo Horizonte: Autêntica, 2010.

BENJAMIM,Walter: Rua de mão única. Obras escolhidas; volume 2. São Paulo, editora brasiliense, 1987.

- Magia e Técnica, arte e politica: ensaios sobre literatura e história da cultura.

Trad. Sérgio Paulo Rouanet. Vl I. São Paulo: Brasiliense, 1987.

Obras escolbidas III. Charles Baudelaire: Um lírico no auge do capitalismo. São Paulo, Brasiliense, 1989.

Paris Capital do Século XIX. In: Passagens. São Paulo: IMESP, 2007.

CAMPOS, Álvaro. Poemas. Disponível em http://casafernandopessoa.cm-lisboa.pt. Acesso em 10.07.2002.

Artigo recebido em: 02 de Agosto de 2012.

Artigo aprovado em: 06 de Novembro de 2012. 